\title{
GOOD AND EVILS OF INDIAN FINTECH COMPANIES IN THE REVOLUTION OF BANKING AND FINANCE SECTOR
}

\author{
Sabita Bhagabati \\ M.Phil Scholar, Department of Commerce, \\ Rajiv Gandhi University, Rono-Hills, Doimukh, Arunachal Pradesh, India
}

\begin{abstract}
According to EY's 2017 FinTech Adoption Index, one-third of consumers utilize at least two or more FinTech adoption by digitally active consumers in Brazil, China, India, Mexico, and South Africa are average 46 percent that is considerably higher than the global average. From an individual market perspective, China and India have higher adoption rates at 69 percent and 52 percent respectively. The present research paper is to find out the positive and negative sides of FinTech innovation adoption in the revolution of the banking and finance sector in India. The Indian government is proactively pushing the use and adoption of technologies to make India a cashless society through instruments like UPI, digital wallets, e-KYC, Aadhaar, and BHIM, etc. Multiple challenges prevent the growth of the FinTech sector in the Indian economy. It is a software-based solution that aids FinTechs in managing the compliance requirements issued by regulatory bodies. It is an end to end mobile-based solution that helps tap the unbanked and underbanked population in the Indian subcontinent. FinTechs enjoy a unique, seamless, loan management system that allows all stakeholders to examine customer data and make more informed decisions during lending. Analytical capabilities, like credit analytics, bank statement analysis, and GST analytics, borrowing helps to become a high profiteering business for FinTechs.
\end{abstract}

Key words: FinTech, Indian Finacial Market, Banking in India

Cite this Article: Sabita Bhagabati, Good and Evils of Indian FinTech Companies in the Revolution of Banking and Finance Sector, International Journal of Management, 11(12), 2020, pp 2245-2251.

http://iaeme.com/Home/issue/IJM?Volume=11\&Issue=12

\section{INTRODUCTION}

During the twenty-first century, FinTech was applied to the technology supported as the back office application system for the established financial institutions. The present era has been shifted to a more consumer-oriented service and therefore a more consumer-oriented approach for FinTech. The term now includes different sectors and industries such as education, retail 
banking, fund-raising and non-profit, and investment management institutions. FinTech helps companies, business owners, and a consumer for managing better their financial operations, processes, and uses the specialized software and algorithms that are used on computers and mostly in smartphones.

The term "financial technology" or "FinTech" can apply to any innovation in how people transact business, from the invention of digital money to double-entry book-keeping. Since the internet revolution and the mobile internet/smartphone revolution, however, financial technology has grown explosively, and FinTech, which originally referred to computer technology applied to the back office of banks or trading firms, now describes a broad variety of technological interventions into personal and commercial finance.

FinTech companies have grown suddenly since the revolution of the internet and mobile internet or smartphone. Originally it was a computer technology that was used by the office of banks or business organizations, now it has been used by the individual and financial institutions exclusively for transacting the business efficiently. FinTech is used by customers and institutions for money transfer, bypassing a bank branch to apply for credit, raising money for starting a business, managing investment with the help of a physical person or manual work.

According to EY's 2017 FinTech Adoption Index, one-third of consumers utilize at least two or more FinTech services and they are aware of the importance of FinTech. The average percentage of digitally active consumers using FinTech services reached 33 percent across the twenty markets. FinTech adoption by digitally active consumers in Brazil, China, India, Mexico, and South Africa are average 46 percent that is considerably higher than the global average. From an individual market perspective, China and India have higher adoption rates at 69 percent and 52 percent respectively. FinTech products and services are used by younger consumers in high volume. 25 to 34 years old consumers are tech-savvy "digital nations" and greater need for financial services. (EY FinTech Adoption Index 2017, 2017)

\section{REVIEW OF LITERATURE}

The author, ( Romānova, Grima, Spiteri, \& Kudinska, 2018)in their research paper mentioned that EU Payment Service Directive (PSD2) allows non-financial companies to provide financial services which is a challenge for the financial service providers like banks and investment agencies. Their paper explored the opportunities and risks for the financial service industry from financial technology developers. Their findings showed customers' satisfaction towards FinTech companies, as these companies provide competitiveness, innovation, and development. High-quality products and services with high-speed transactions with security and privacy are perceived as important for FinTech users.

The authors, ( Saksonova \& Merlino, 2017) identified the advantage and disadvantages of FinTech services offered by the traditional financial sector companies. Their paper surveyed Latvian society, whether they were ready to use FinTech services instead of traditional banking services. The results showed that respondents were unaware of FinTech services in Latvia and these companies' innovations and financial products.

The authors, (Suprun, Petrishina, \& Vasylchuk, 2020) researched the relation between FinTech companies and traditional financial institutions. The article explored both the competitive and co-operative aspects of financial market participants in a digital economy. Their study revealed that traditional institutions should reformat their architecture to become digital. 


\section{STATEMENT OF PROBLEM}

The FinTech companies' developments create the growing use of application programming interfaces (APIs) in financial services and payments; big data analytics and the role of artificial intelligence, machine learning, and deep learning; biometric technologies for identity authentication; cloud competing to enable payment delivery models; and contactless technologies. India has been placed second by the EY's 2017 FinTech Adoption Index with 52 percent of individuals adopting FinTech for financial services. Besides this, Indian National Statistical Commission surveyed literacy in India estimated to be 77.7 percent in 2017-18. Therefore it is important to understand the good and evils of using FinTech as technology innovation. Proper adoption of FinTech innovation for customer satisfaction and national development, by the financial institutions and banks, is very important as the new technology also creates numerous problems of cybercrime in terms of affecting the halfeducated customers.

\section{OBJECTIVES}

The only objective of the present research paper is to find out the positive and negative sides of FinTech innovation adoption in the revolution of the banking and finance sector in India.

\section{METHODOLOGY}

The investigation in the present research paper is completely based on secondary sources of data. Different journals, websites, webpages relating to FinTech are studied to present the objective of the paper. Positive and negative revolution in the banking and financial sector from FinTech are explored, based on the adoption of FinTech by the Indian financial sector.

\section{ANALYSIS AND INTERPRETATION}

The Global investments in FinTech ventures have exceptionally large in recent years with increasing growth. This is evidence that the digital revolution is at the doorsteps of the financial services sector. This revolution is having a huge impact on all the banks and financial institutions globally. FinTech is the use of digital technology by startups to come up with innovative products and services such as mobile payments, alternative finance, online banking, big data, and overall financial management. FinTech was introduced as a technology that was used at the back-end systems of financial institutions and banks. Now it encompasses several applications that are consumer-based. By 2019, we can trade stocks, manage funds, and pay for your insurance and food via this technology.

The FinTech for banking has impacted various applications and revolutionized the way consumers access their finances. Its impact ranges from mobile payment apps like Square to investment and insurance companies. FinTech is the best option to carry out financial inclusion since it's developed to provide consumers direct access to their finances through simple yet cutting-edge technology.

This impact of FinTech can also be seen as a potential threat to traditional banks. In today's digital era, customers don't want to go for services provided by the traditional financial services industry. They prefer services that are quick and safe. This is the reason that FinTech is gaining popularity and causing disruption in banking and other financial services. According to a study did in 2016, a vast majority of Americans (84 percent) use FinTech for managing their finances. Besides, the majority of them use between one to three apps to manage their finances. Around 69 percent use these apps at least a few times a week and around one-third use them daily. Currently, there are approx. 1.7 billion people worldwide without any bank accounts. FinTech comes as a savior for all those people by providing an easy option to participate and access financial services without any need for a bank account. 
FinTech has transformed the Indian market with digital payments, lending, and investments. India's adoption rate for FinTech products stands at 59\%, which is the secondhighest pace worldwide. The demonetization in 2016 in India was the moment that redefined the FinTech ecosystem as it was understood until then and put many FinTech startups in India on the map. The ban of currency notes forced the public to switch to digital payments and online transactions overnight. Digital banks, payment wallets, UPI apps, internet banking to digital lending and insurance are viewed as a potentially transformative force in the Indian market. FinTech startups work on the intersection of finance and technology, help to bring efficiencies in the current process, and streamlined the distribution chain of digital payments and transactions. It has improved the completion rate of payments and has helped revolutionize e-commerce, hyper-local delivery, online services, and more. FinTech startups such as Paytm, MobiKwik, Oxigen, PhonePe, PolicyBazaar among others were around before 2016, post-demonetization they gained great momentum and turned into overnight successful companies.

PhonePe was the leading app for UPI payments in India. It offers just one app to enable users to send or receive money, make mobile or DTH recharges, paying utility bills from credit card to insurance premiums, shopping through online and offline vendors, or traveling. The user just needs to link their bank account to the PhonePe app and make payments through the unified payments interface (UPI) platform.

MobiKwik is an issuer-independent digital financial services platform; the company has forayed into various segments of the FinTech ecosystem including digital wallets, wealth management, insurance, and more. Low customer acquisition cost, inbuilt scoring model, and quick disbursal of loans have been the key differentiators for MobiKwik. MobiKwik was one of the first to disburse a loan amount in a matter of 90 seconds.

Consumers use ETMONEY to invest in Zero-commission direct mutual funds for Free, protect their families with unique Insurance solutions \& use ETMONEY Credit Card to take instant loans at low-cost. Growing at 340\% yearly, combined with multiple innovative solutions, it has grown to seven million users from more than $1300+$ Indian cities and is driving more than $\$ 500$ million of non-payment annual transaction volume on its platform.

PolicyBazaar is an insurance aggregator that was started to provide transparent and accurate insurance information to consumers. A platform where consumers could not only understand the tools which would suit them best for insurance but also a platform on which they could compare products and choose the most viable option.

There is a widespread internet penetration in the Indian subcontinent, with multiple players in the market and governmental policies that focus on digitization have led to an increase in investments in the FinTech sector from venture capitalists. FinTech start-ups are revolutionizing the financial services aspect in India. New developments like mobile wallets and the Unified Payment Interface (UPI) platform are significant contributors to the adoption of mobile technologies in financial transactions recently. The Indian population today has advantages like easy account setup, easy access to a wide variety of financial services, and 24/7 access that FinTech companies offer. Also, individuals are favoring innovative products from FinTechs when compared to traditional financial institutions. A sudden rise in the number of FinTech start-ups in the Indian finance sector has contributed to the growth of many other sectors through their efficient financial strategies. The scope drives the industry in itself for growth and profitability. 


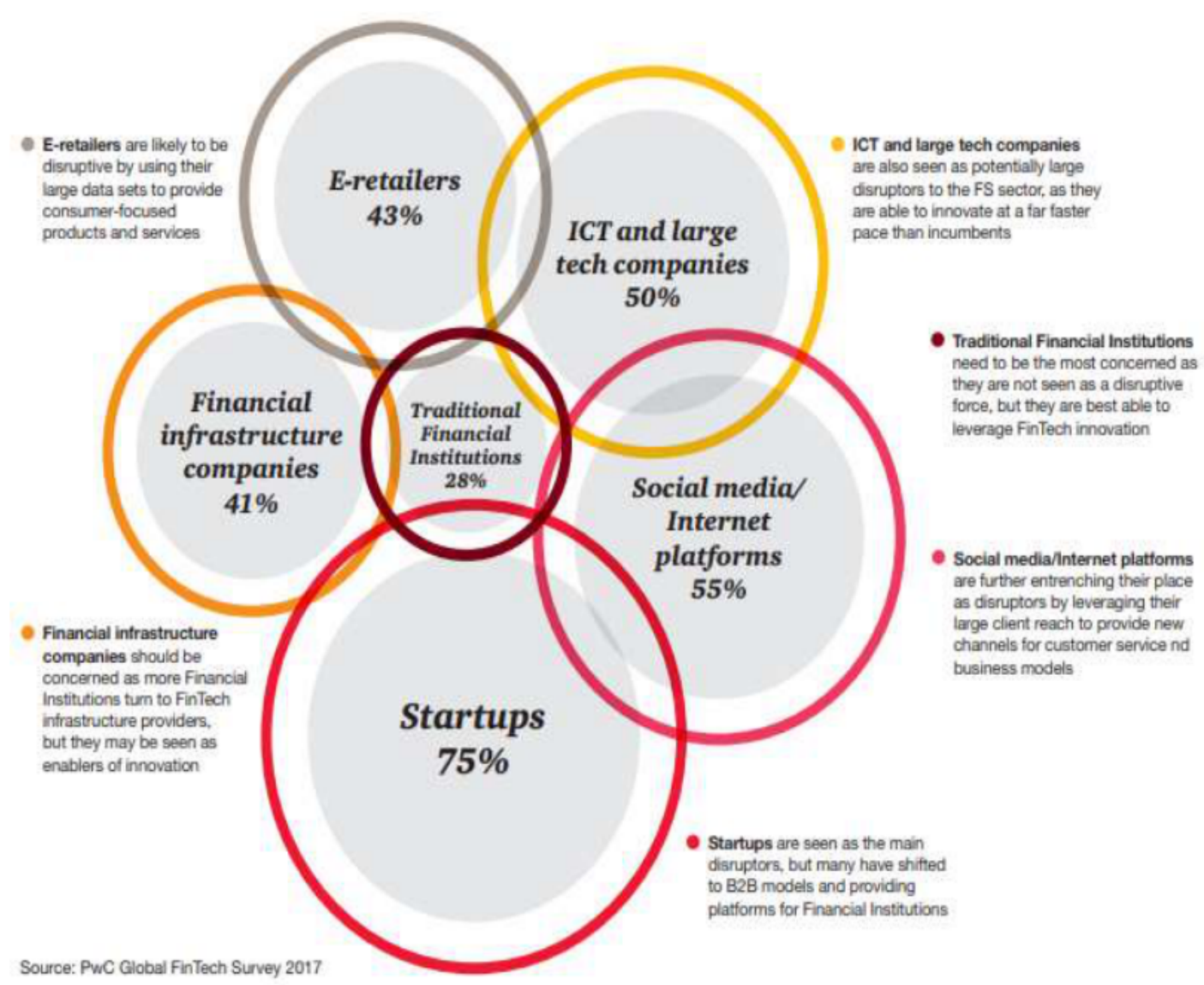

Figure 1

Table 1

\begin{tabular}{|l|l|l|}
\hline FinTech Adoption Rates of India & Rates (in percent) & Global Average Rates (in percent) \\
\hline Money transfer and payments & 72 & 50 \\
\hline Financial Planning & 20 & 10 \\
\hline Savings and investments & 39 & 20 \\
\hline Borrowing & 20 & 10 \\
\hline Insurance & 47 & 24 \\
\hline
\end{tabular}

Source: EY FinTech Adoption Index 2017

The FinTech start-ups have faced multiple challenges in India every day.

Regulatory laws and compliance inevitably contribute to the slowdown of the FinTech start-ups in Indian financial markets. They also make it difficult for FinTech players to enter the Indian markets. Compliance laws are laid in place as a restrictive regulatory framework to prevent fraud. However, they too act as massive barriers for the new FinTech entrants. There is a big list of formalities that FinTech start-ups need to fulfill before they even start operations. These laws stood as evils for the FinTech players in Indian Financial Market.

FinTechs had staggered growth because of poor infrastructures like low internet penetration and literacy levels in India. A large segment of the Indian population is unbanked and prefer cash transactions rather than online purchases. Another hurdle for FinTech growth in India is low financial literacy in the Indian community. A World Bank report says that India launched the Pradhan Mantri Jan Dhan Yojana to improve financial inclusion in the country. After opening a total of 180 billion bank accounts, more than a 48percent of them remained dormant without a single transaction in a year. Despite all the initiatives in place, India is far from the road to financial inclusion. 
Most Indians follow a conservative for daily transactions and like to use cash for ending a day. They think money is a medium of sales for ages and find it difficult to change their habits and adapt to new avenues. Providing financial services in an unbanked market is difficult since these services are often related to digital scams. Several Indians fail to see the use of FinTechs that offer through their innovative products and service due to financial illiteracy.

FinTech companies use massive customer data. Multiple cybersecurity threats result in massive monetary losses during online transactions that are completely unwarranted for customers. The technology that offers convenience also opens up people's online accounts to fraudsters looking to steal their assets. This is a constant stream to the popularity of FinTechs. These need to fortify against any challenge posed by hackers. A massive amount of financial data of individuals and companies is made available digitally. This increases the risk of cybersecurity breaches.

\section{THE WAY AHEAD}

The Indian government is proactively pushing the use and adoption of technologies to make India a cashless society through instruments like UPI, digital wallets, e-KYC, Aadhaar, and BHIM, etc. Post demonetization, the number of FinTech start-ups in India saw a sudden rise. These start-ups are working in various sub-sectors of the FinTech market, such as mobile POS (point of sale), peer-to-peer (P2P) transactions, lending, and insurance, among others. They initiate creative innovations in the fields of finances and technology. Also, multiple challenges prevent the growth of the FinTech sector in the Indian economy. It is a softwarebased solution that aids FinTechs in managing the compliance requirements issued by regulatory bodies. It is an end to end mobile-based solution that helps tap the unbanked and underbanked population in the Indian subcontinent. FinTechs enjoy a unique, seamless, loan management system that allows all stakeholders to examine customer data and make more informed decisions during lending. Analytical capabilities, like credit analytics, bank statement analysis, and GST analytics, borrowing helps to become a high profiteering business for FinTechs.

\section{REFERENCES}

[1] Romānova, I., Grima, S., Spiteri, J., \& Kudinska, M. (2018). The Payment Services Directive II and Competitiveness: The Perspective of European FinTech Companies. European Research Studies Journal, 3-22.

[2] Saksonova, S., \& Merlino, I. K. (2017). FinTech as Financial Innovation - The Possibilities and Problems of Implementation. European Research Studies Journal, 961-973.

[3] EY FinTech Adoption Index 2017. (2017). Retrieved October 2020, from assets.ey.com: https://assets.ey.com/content/dam/ey-sites/ey-com/en_gl/topics/banking-an

[4] 6 Key Challenges That FinTech Startups Face in India. (2020, June). Retrieved October 2020, from finezza.in/blog: https://finezza.in/blog/6-key-challenges-that-FinTech-startups-face-inindia/

[5] Financial Technology \& Automated Investing Financial Technology. (2020, August).

Retrieved October 2020, from Investopedia:

https://www.investopedia.com/terms/f/FinTech.asp

[6] Literacy in India. (2020). Retrieved December 2020, from Wikipedia:

https://en.wikipedia.org/wiki/Literacy_in_India 
[7] GRAHAM, A. (n.d.). FinTech and Banks: How Can the Banking Industry Respond to the Threat of Disruption? Retrieved October 2020, from Finance:

https://www.toptal.com/finance/investment-banking-freelancer/FinTech-and-banks

[8] Gundaniya, N. (2020). what is FinTech and how it has impacted banking? Retrieved 2020, from digipay.guru/blog/the-impact-of-FinTech-on-banks-and-financial-services:

https://www.digipay.guru/blog/the-impact-of-FinTech-on-banks-and-financial-services/

[9] Kundariya, H. (2019, December 9). The Challenges Of FinTech Application In Modern EraA Comprehensive Guide. Retrieved October 2020, from customer, think: https://customerthink.com/the-challenges-of-FinTech-application-in-modern-era-acomprehensive-guide/

[10] Perzhanovskiy, N. (2020, November). How Fintech Affects Banks and Financial Services? Retrieved December 2020, from justcoded: https://justcoded.com/blog/the-impact-of-FinTechon-banks-and-financial-services/

[11] Sahni, A. (2019, October). Which Are The Most Successful FinTech Startups In India? Retrieved October 2020, from inc42: https://inc42.com/features/which-are-the-mostsuccessful-FinTech-startups-in-india/

[12] Shaw, A. (2020, March). Financial inclusion and the role of FinTech. Retrieved October 2020, from Australian-banking-and-finance/news/: https://www.rfigroup.com/australianbanking-and-finance/news/financial-inclusion-and-role-FinTech

[13] Suprun, A., Petrishina, T., \& Vasylchuk, I. (2020). Competition and cooperation between FinTech companies and traditional financial institutions. E3S Web of Conferences 166, 13028 (2020).

[14] Wingard, L. (n.d.). Top 10 Banking Industry Challenges - And How You Can Overcome Them. Retrieved 2020, from global.Hitachi-solutions: https://global.hitachisolutions.com/blog/top-10-challenges-banking-financial-organizations-can-overcome 